\title{
Virtual simulation system for prosthodontics. Part I
}

\author{
Sistemul de simulare virtuală pentru protetica dentară. Partea I
}

\author{
Simona Andreea Sandu' ${ }^{1}$ Călin Dan Neamțu², Sorin Dan Grigorescu ${ }^{3}$, \\ Ionel Bujorel Păvăloiư ${ }^{3}$ \\ ${ }^{1}$ Universitatea de Medicină şi Farmacie „Carol Davila“, Bucureşti, România \\ 2Universitatea Tehnică Cluj-Napoca, România \\ ${ }^{3}$ Universitatea Politehnică, Bucureşti, România
}

\begin{abstract}
Current computerized technologies introduced into dental prosthetics use 3D imaging, simulation systems, virtual reality. The virtual reality system, based on haptic technology, is a new instrument in the teaching process, still developing. The necessity to implement virtual reality technology has emerged from the fact that medical practice has been restricted to patients in recent years. Virtual reality systems have been introduced in order to practice certain clinical maneuvers and to acquire specific skills. Actual, virtual technology is at the stage where offers advanced simulations to users by combining visual and tactile response. The efficiency of e-learning platforms is increased when including virtual reality technologies. Thus, a new, interactive concept is introduced.
\end{abstract}

Keywords: prosthetics, e-learning, virtual reality

\section{REZUMAT}

Tehnologiile computerizate actuale, introduse în protetica dentară, folosesc imagistica 3D, sisteme de simulare, realitatea virtuală. Sistemul de realitate virtuală, bazat pe tehnologia haptică, reprezintă un instrument nou în procesul de predare, încă în curs de dezvoltare. Necesitatea implementării tehnologiei realităţii virtuale a reieşit din faptul că practica medicală a fost restrânsă pe pacienţi în ultimii ani. Sistemele de realitate virtuală au fost introduse în scopul exersării anumitor manopere clinice şi dobândirii manualităţii specifice. Actual, tehnologia virtuală este în stadiul în care oferă utilizatorului simulări avansate, prin combinarea răspunsului vizual cu cel tactil. Eficienţa platformelor de e-learning este crescută atunci când înglobează tehnologiile realitătii virtuale. Astfel, este introdus un concept nou, interactiv.

Cuvinte cheie: protetică, realitate virtuală, e-learning

\section{INTRODUCERE}

Tehnologiile actuale, introduse în protetica dentară, folosesc imagistica 3D, sisteme de simulare, realitatea virtuală. Realitatea virtuală reprezintă o simulare electronică a unui mediu, care poate realiza interacțiunea cu utilizatorul în situații tridimensionale. Strategia simulării virtuale presupune corelația dintre conținutul ştiințific, dotarea IT şi simulatorul haptic (1).

Sistemul de realitate virtuală, având ca bază tehnologia haptică, este un instrument nou, încă în curs de dezvoltare, în procesul de de predare şi formare în protetica dentară. Necesitatea implementării tehnologiei realității virtuale a reieşit din faptul că practica medicală a fost restrânsă pe pacienți în ultimii ani. Sistemele de realitate virtuală au fost introduse în scopul exersării anumitor manopere clinice şi dobândirii manualităţii specifice. Sistemele de simulare sunt programe interactive care simulează situațiile clinice reale în care studenții exersează manopere profesionale. Realitatea virtuală oferă evaluarea preparațiilor în timpul pregătirii 
dinților, oferind un feedback adecvat. De asemenea, sistemul de simulare permite repetabilitatea manoperelor clinice, având ca rezultat dobândirea manualității. Diferența caracteristică între preparațiile virtuale şi metodele tradiționale exersate pe modele din ghips sau plastic este că permite utilizatorilor să primească o forță feedback realistă asemănătoare cu practica pe dinții reali.

Preparațiile virtuale se obțin prin folosirea de către utilizator a dispozitivului haptic, care are ca reprezentare virtuală $3 \mathrm{D}$, având modele de instrumentar dentar real şi executând mişcări pe modele virtuale $3 \mathrm{D}$ ale dinților. Acestea substituie folosirea frezelor reale pe dinții pacienților $(2,3)$.

În funcție de procedura dentară simulată, feedback-ul simulatorului angajat este reprezentat de schimbările topologice ale structurii dintelui (smalț şi dentină) sau forțe (senzații) în mâna utilizatorului. Senzațiile sunt similare cu cele resimțite de utilizator, atunci când execută aceeaşi procedură dentară pe un pacient.

Tehnologia realităţii virtuale a ajuns în stadiul de dezvoltare în care oferă utilizatorului simulări multimodale avansate (răspuns vizual combinat cu răspuns tactil). Astfel, sunt sensibil îmbunătățite atât senzația prezenței la nivelul utilizatorului în cadrul mediilor virtuale cât şi interacțiunea dintre utilizator şi mediul simulat.

Dispozitivul haptic ataşat la computer permite obținerea de senzații tactile datorită interacțiunii cu calculatorul.

Diferențele dintre particularitățile componentelor simţului tactil sunt folosite în tehnologiile realității virtuale. În aplicații de realitate virtuală, sunt două tipuri de interfețe:

a. Interfețe cu feedback-ul tactil, folosite pentru a explora suprafața de contact a unui obiect virtual;

b. Interfețe cu force feedback, utilizate în aplicațiile în care forțele de contact sunt date în timpul interacțiunii utilizatorului.

Aceste tipuri de interfețe pote fi construite în mod independent sau pot fi combinate. Atunci când sunt combinate, acestea sunt denumite interfețe feedback haptic.

Simulatoarele dentare redau situații clinice reale datorită combinației dintre componenta vizuală (imaginea de pe monitor) şi cea tactilă (senzația conferită de haptic). Aplicațiile în cadrul mediului de simulare 3D se pot utiliza sincron (cu întreaga grupă de studenţi) sau asincron, individual.

În medicina dentară, modelele de studiu sunt o parte esențială a înregistrărilor clinice. Modelele de ghips tradiționale sunt convertite în cadrul tehnologiilor digitale în modele virtuale, folosind imagistica 3D (4). Modelele 3D sunt un concept relativ nou de inovație. Prin urmare, folosirea modelelor virtuale ca resursă în procesul de predare este o metodă supusă analizei. În domeniul educaţiei dentare, modelele virtuale nu au constituit o caracteristică extinsă a resurselor de predare şi învățare în domeniul dentar. Transformarea modelelor solide în modele virtuale de predare şi resurse de învăţare are câteva avantaje. Studiul modelelor virtuale pe calculator, în 3D, conferă mobilitate şi flexibilitate. Studenții vor avea acces individual la un set de modele virtuale. Nu în ultimul rând, prin crearea de resurse de învățare pe baza modelelor virtuale, utilizatorii vor dobândi experiență cu manipularea datelor dentare electronice de evidență.

\section{METODE}

Sistemul de simulare virtuală conceput pentru protetica dentară presupune interactiunea utilizatorului cu un mediu virtual 3D folosind un dispozitiv haptic. Modelul propus simulează executarea manoperelor clinice pentru preparațiile dentare pe bază de şlefuire-reducere a țesuturilor dentare.

În cadrul proiectului de cercetare, aplicațiile dezvoltate necesită conectarea dispozitivelor haptice cu stațiile grafice achiziționate. S-au creat două unități de lucru în mediul virtual, compuse din dispozitivul haptic Geomagic Touch şi staţile grafice Fujitsu.

\section{Dispozitivul haptic Geomagic Touch}

Dispozitivul haptic Geomagic Touch beneficiază de force-feedback (Fig. 1).

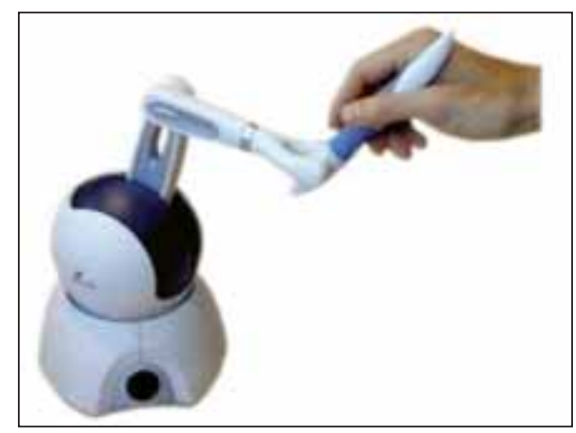

FIGURA 1. Dispozitivul haptic Geomagic Touch 
Aceasta conferă interacțiunea dintre instrumentele virtuale coordonate de utilizator şi țesuturile dentare virtuale cu care acesta intră în contact. Dispozitivul haptic Geomagic Touch permite interacțiunea cu realitatea virtuală prin atingerea, modificarea sau manipularea obiectelor virtuale. Acest lucru este posibil datorită tehnologiei force-feedback (Fig. 2).

Prin simularea torsiunii combinată cu efecte de force feedback este posibil să se simtă forțe de coliziune şi reacțiune precum şi cele de răsucire a unei componente dintr-un sistem mecanic virtual sau unul real în cazul unui braț de robot comandat de la distanţă.

Dispozitivul haptic portabil Geomagic Touch are următoarele specificații:

- design ergonomic;

- include software cu specificaţii, printre care: navigare 3D cu atingere şi force feedback la aplicațiile create. Platforma are la bază API OpenGL ${ }^{\circledR}$.

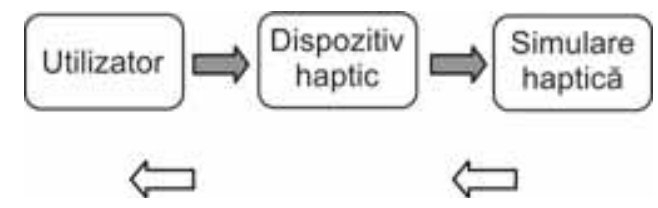

FIGURA 2. Interacțiunea utilizator şi simulare haptică

\section{Stațile grafice Fujitsu}

Calitatea şi performanţa de redare grafică într-o simulare virtuală sunt cele mai importante criterii care determină realismul simulării.

Stațile grafice Fujitsu suportă creativitatea, simularea şi vizualizarea la un nivel professional ridicat. Sunt utilizate în diverse domenii, cum ar fi CAD, CAE, AEC, Oil \& Gas, HPC sau în domeniul medical. Selecția de procesoare, hard discuri şi car- duri grafice profesionale conferă o fiabilitate mărită, performanţă şi posibilitatea de upgrade la o capacitate de memorie semnificativ mărită faţă de staţiile de lucru obişnuite. SATA (Serial Advanced Technology Attachment) este tehnologia standard pentru conectare şi transferul datelor din driverele hard discurilor la sistemul computerului.

Monitorul 3D Fujitsu permite utilizatorilor aplicații 3D, din domeniul graficii asistate de calculator, care utilizează programe solicitante, precum CAD/CAE, simulatoare medicale sau sisteme de procesare a datelor.

Ochelarii 3D permit vizualizarea imaginilor tridimensionale şi sunt clasificaţi în funcție de principiul de redare a imaginii. Ochelarii 3D Fujitsu au ca principiu de funcționare polarizarea lentilelor, care se poate realiza linear sau circular, în funcție de sistemul care redă conținutul 3D. Polarizarea este realizată de tehnologia pasivă 3D, astfel încât dispozitivul de afişare 3D rulează simultan imaginile corespunzătoare celor doi ochi, pentru ca să fie recepționate diferențiat de lentilele ochelarilor. Calitatea vizualizării 3D este foarte bună. Sunt compatibili cu tehnologia 3D specific implementată atât pe sistemul de redare (stație grafică) cât şi pe cel de vizualizare (monitor 3D).

\section{Modelele 3D}

Modelele 3D au fost create pentru a fi utilizate în softul de protetică dentară în exemplificarea diferitelor tipuri de manopere specifice acestui domeniu (Fig. 3). Pentru a replica în mediul virtual o serie de studii de caz reale şi reprezentative s-a ales metoda de digitizare - scanarea laser.

Scanarea laser $3 D$ reprezintă procesul de copiere sau reprezentare digitală a geometriei obiectelor solide folosind laserul (5).
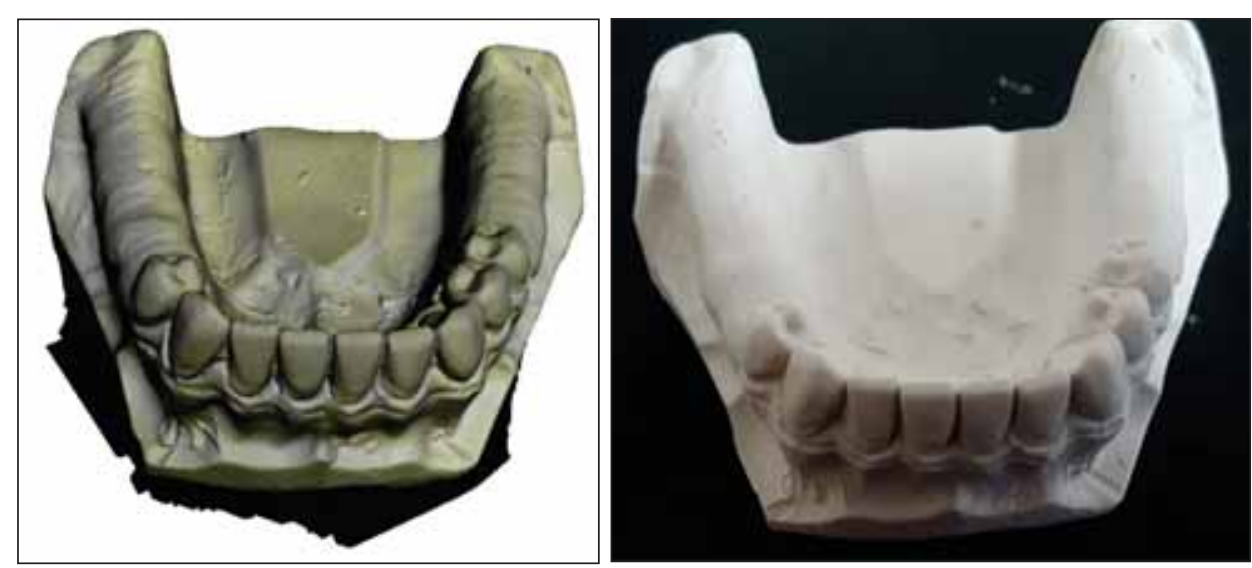

FIGURA 3. Modele 3D vs. modele din ghips 
Modelele 3D, care vor fi utilizate în aplicația dezvoltată, s-au obținut urmând paşii prezentați mai jos:

1. obținerea modelului dentar real al unui caz reprezentativ se face utilizând instrumente specifice;

2. scanarea modelului dentar utilizând un scaner cu lumina structurată cu o precizie de aproximativ $50 \mu \mathrm{m}$;

3. procesarea primară a scanării presupune filtrarea şi îndepărtarea punctelor scanate în aer sau pe suportul amprentei reale şi generarea mesh-ului $3 \mathrm{D}$

4. conversia mesh-ului în suprafață s-a realizat în Catia V5. În prima fază, mesh-ul a fost filtrat şi omogenizat. În a doua etapă, a fost convertit în suprafață cu o deviaţie maximă de $0,01 \mathrm{~mm}$;

5. suprafața a fost convertită în corp solid. Acest lucru este necesar pentru simularea îndepărtării straturilor în aplicaţia dezvoltată;

6. prin operații specifice softurilor CAD se creează mai multe straturi la care se vor definii densităţi diferite, acestea vor fi „,simţite“ diferit cu dispozitivul haptic de către cursanți;

7. operația de texturare are rolul de a crea un efect foto realistic pentru modelul 3D.

\section{Factorii care condiționează simularea virtuală}

Şlefuirea dintelui este o manoperă clinică omniprezentă în protetica dentară. Acest proces implică procedeul de şlefuire cu ajutorul frezelor de turbină, pentru a modifica forma dintelui. În timpul acestei manopere, dacă se aplică prea multă forță, va creşte rata de generare de căldură şi, prin urmare, deteriorarea țesuturilor dentare, în timp ce prea puțină forță poate prelungi procedura de tratament, devenind dureroasă pentru pacient. Prin urmare, senzația tactilă este foarte importantă pentru preparațiile dentare. În timpul şlefuirii, forța de feedback este generată de forța de interacțiune dintre dinte şi freza dentară de turbină. Factorii care influențează forța de şlefuire sunt forma frezei, comportamentul piesei de mână, secțiunea dentară diferită (smalț sau dentină) şi mediul înconjurător (6). Dintele este static, iar freza dentară face mişcări de rotație şi de translație. Forțele diferite care acționează sunt calculate utilizând cuplarea virtuală ca să se păstreze stabilitatea. Forța de feedback trebuie să fie în concordanţă cu forța reală de şlefuire.
Aceste principii aplicate în cazul şlefuirii dintelui sunt transpuse în mediul virtual de simulare. Dispozitivul haptic generează o forță de feedback tactil, asemănătoare cu cea resimțită la şlefuirea diferențiată a smalţului şi dentinei. Aceste metode sunt implementate în sistemul virtual de pregătire.

Realitatea unui mediu de simulare având şi efect de feedback depinde de mai mulți factori, printre care calitatea modelelor $3 \mathrm{D}$, realitatea forțelor de feedback. Pentru acuratețea simulării se ține cont de: datele şi structura dintelui care urmează să fie simulat, proprietățile biomecanice, modelul utilizat pentru a evalua forțele pentru feedback (7).

Din punct de vedere al structurii dintelui, pregătirile menționate abordează țiesuturile dentare, smalțul şi dentina. Pentru aplicația virtuală este concludentă diferența de duritate a acestora. Smalțul, cu o grosime de $2 \mathrm{~mm}$, care acoperă dentina, este țesutul cel mai dur din corpul uman, mai dur decât țesutul osos. Dentina este elastică şi compresibilă, în contrast cu natura predispusă la fisurare a smaltului.

Studiile din literatura de specialitate, referitoare la proprietățile biomecanice ale dintelui, se axează pe modulul de elasticitate şi pe duritatea acestuia. Publicațiile relevă faptul că proprietățile biomecanice ale dintelui variază individual, raportat la vârsta pacientului, în funcție de stratul de smalț sau dentină.

Proprietățile biomecanice ale unei structuri pe care se intervine influențează forțele de palpare (atingere) şi de şlefuire. În literatura de specialitate, studiile prezintă câteva aspecte (8). Modulul de elasticitate şi coeficientul de amortizare al structurii sunt proprietăţile care afectează forța în timpul palpării. Modulul de elasticitate reprezintă cantitatea de stres care ar trebui să fie aplicată pentru a crea o unitate de solicitare într-un material. Este independent de geometria materialului, în timp ce constanta de rigiditate se calculează folosind lungimea, suprafaţa secțiunii transversale şi modulul de elasticitate. Coeficientul de amortizare al structurii este dat de forța de frecare a materialului asupra vitezei de elongație a unităţii.

Există studii care implementează operația de şlefuire prin utilizarea dispozitivului haptic (9). Astfel, a fost stabilit un model matematic al principalilor parametri, care includ diametrul, viteza de rotație a instrumentarului (uzual freza sferică), 
zona de contact cu dintele a instrumentarului şi grosimea stratului şlefuit. Prin folosirea acestui model matematic, care a fost testat prin experimente, s-a stabilit o relație între factorii de mai sus şi forța de şlefuire. Pe lângă aceşti factori, stratul dentar asupra căruia se intervine (smalț sau dentină) şi tipul de instrumentar sunt de asemenea luate în considerare. Diferențele biomecanice ale straturilor de smalț şi dentină şi efectul acestor diferențe asupra dispozitivului haptic sunt esențiale în realizarea unei simulări virtuale.

Provocarea în simulările virtuale este de a obține forțe realiste prin utilizarea dispozitivelor haptice. Totuşi, există unele restricții de hardware, cum ar fi rigiditatea maximă, forța maximă pe care o pot furniza dispozitivele haptice.

În literatura de specialitate, forțele haptice au fost evaluate. Ideea principală a metodei puse în aplicare depinde de redarea a două instrumente separate, instrumentul fizic şi instrumentul virtual (10). Orientarea şi poziţia instrumentului fizic sunt setate identic cu poziția şi orientarea dispozitivului haptic. Utilizatorul simte o forță de contact proporțională cu distanţa dintre instrumentul fizic şi cel virtual, în timp ce instrumentul virtual este redat pe suprafața dintelui. Poziţia şi orientarea instrumentului virtual sunt setate identic cu poziţia şi orientarea instrumentului fizic, dacă nu există nici o coliziune între instrumentul virtual şi dinte. În caz de coliziune, primul punct de contact al instrumentului virtual cu dintele este etichetat pentru a fi utilizat pentru actualizarea poziţiei instrumentului virtual.

Tehnologia haptică permite simularea forțelor de interacțiune (force-feedback), dar este limitată din punct de vedere al realizării feedback-ului tactil. Totuşi este posibilă redarea proprietăţilor de suprafaţă a obiectelor rigide prin folosirea texturilor şi a proprietăților de deformare ale obiectelor prin folosirea unor funcții specifice.

Librăria OpenHaptics a fost utilizată pentru simularea virtuală (11). Toolkit-ul OpenHaptics conceput de compania Sensable (SenseAble, 2014), actual 3D Systems, include interfaţa QuickHaptics, interfața dispozitivului haptic (HDAPI), interfața bibliotecii haptice (HLAPI), utilități, drivere pentru dispozitivul Geomagic Touch. Biblioteca suportă atât sistemul Windows cât şi mediile Linux.
Modelul 3D cu două straturi solide utilizat la testarea modului de lucru cu dispozitivul haptic este prezentat în Fig. 4.

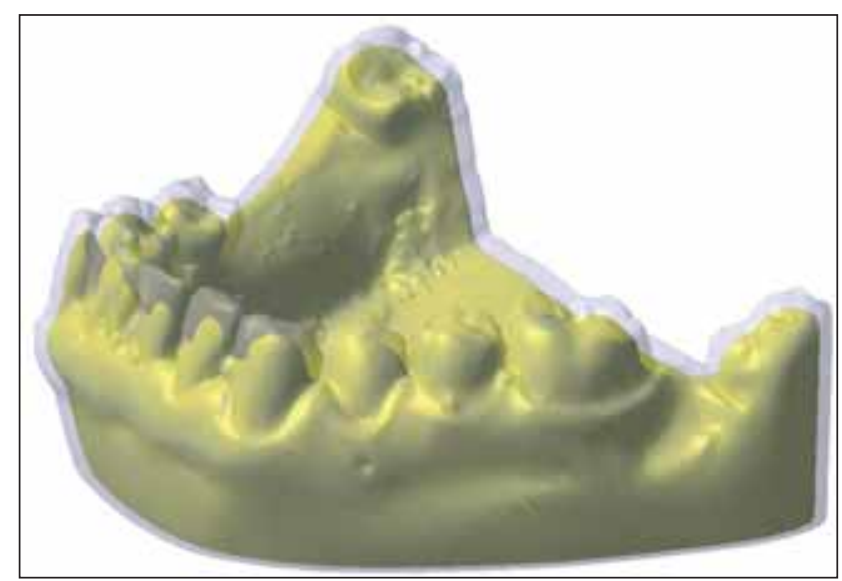

FIGURA 4. Model 3D solid după o amprentă dentară

Pentru soluția software s-au testat două scenarii: una cu manechin şi una fără (Fig. 5). Redarea grafică a fost realizată cu ajutorul bibliotecii Open GL a dispozitivului haptic.

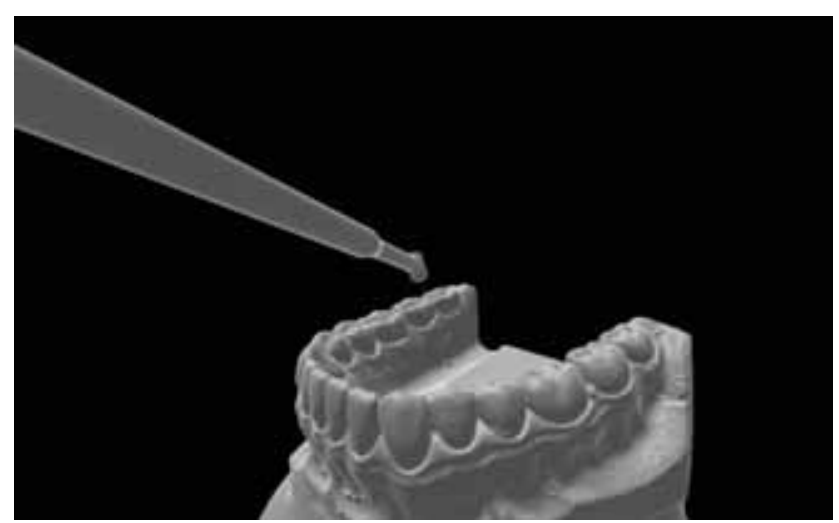

FIGURA 5. Scenariile luate în calcul la dezvoltarea

aplicației - prima variantă

În cadrul soluției propuse, utilizatorul beneficiază de dispozitivele de interacțiune: hapticul Geomagic Touch, tastatură, mouse. Acestea materializează acțiunile permise utilizatorului şi realizarea lor în cadrul mediului simulat. În particular, redarea simţului tactil va fi realizată prin implementarea unei forțe de reacție care va fi transmisă şi simţită de utilizator prin intermediul creionului dispozitivului haptic. Preparațiile dentare simulate sunt specifice proteticii dentare.

\section{REZULTATE ŞI DISCUȚII}

Tehnologia computerizată, prin e-learning, a schimbat modul utilizatorilor de a accesa informa- 
ții. Tehnologiile realității virtuale pot fi înglobate în sistemul de e-learning, determinând creşterea impactului acestora. Integrarea tehnologiei în practica medicală academică depinde şi de măsura în care aceasta contribuie la generarea de cunoştințe. În cadrul majorității sistemelor de simulare bazate pe tehnologia realității virtuale, problematica referitoare la protetica dentară este foarte puțin sau aproape deloc abordată.

Introducerea tehnologiei de realitate virtuală în platforma de e-learning este o abordare inovativă, fiind concepută pentru protetica dentară.

Manoperele clinice specifice pot fi învăţate datorită posibilităţilor de repetare şi autoevaluare, având ca scop dobândirea manualității. Preparațiile virtuale se efectuează fără a produce prejudicii pacienţilor. Experiența de învățare este realistică, datorită utilizării tehnologiei haptice, fiind supusă unui proces continuu de perfecționare.

\section{BIBLIOGRAFIE}

1. Sandu Simona Andreea, Neamțu C.D., Grigorescu S.D., Bănică C. K., Babiuc luliana, Bisoc Adriana,

Constantinovici A., Utilizarea tehnologiei de realitate virtuală în protetica dentară. Revista Română de Stomatologie, Nr. 2, Vol. LXI, 2015, ISSN 1843-0805

2. Pavaloiu I.B., Ioanitescu R., Dragoi G., Grigorescu S., Sandu Simona Andreea, Virtual reality for education and training in dentistry, the 12th International Scientific Conference e-learning and software for education, Bucharest, April 21-22, 2016 10.12753/2066-026x-16-052

3. Pavaloiu I.B., Sandu S.A., Grigorescu S., Dragoi G., Inexpensive dentistry training using virtual reality tools, Proceedings of inted2016 Conference 7th-9th March 2016, Valencia, Spain ISBN: 978-84-608-5617-7

4. Brusco N., Andreetto M., Lucchese L., Carmignato S. and Cortelazzo G.M. (2007). Metrological validation for 3D modeling of dental plaster casts. Medical Engineering and Physics Volume: 29 Issue: (9) Pages: 954-966 ISSN: 13504533 (ISSN).

5. Hayashi K., Sachdeva A.U.C., Saitoh S., Lee S. P., Kubota T., Mizoguchi I. (2013). Assessment of the accuracy

\section{CONCLUZII}

Sistemul de realitate virtuală pentru protetica dentară a fost conceput ca un instrument de învățare şi exersare a unor manopere clinice uzuale, complementar cursurilor şi stagiilor universitare. Acesta beneficiază de un program interactiv şi se înscrie în tendințele actuale întâlnite la universități de prestigiu, la care aceste sisteme sunt introduse în curriculă.

\section{Acknowledgements}

Acest articol a fost realizat în cadrul programului de cercetare PN II - PCCA, intitulat "Platformă virtuală de e-learning bazată pe aplicații $3 \mathrm{D}$, utilizabilă în protetica dentară".

Conflict of interest: none declared

and reliability of new 3-dimensional scanning devices. American Journal of Orthodontics and Dentofacial Orthopedics Volume: 144 Issue: (4) Pages: 619-625 ISSN: 08895406 (ISSN).

6. Jafar Usman A.M., Andonissamy L., Elsirint Asim, Boon Of Virtual Reality And Its Applications As An Educational Tool In Dentistry: A Review, Int J Pharm 2015; 5(3):680-684

7. Liu G., Zhang Y. and Wang D. (2005). Cutting Force Model of Dental Training System. In Proceeding of IEEE IROS 2005, 925-929.

8. Ostwald P.F., Munoz J. Manufacturing Processes and Systems. pp 270-330. (1997)

9. Balijepalli A., Kesavadas T. (2003). A Haptic Based Virtual Grinding Tool, IEEE Virtual Reality Symposium 2003, March 22-26, Los Angeles, CA.

10. Ho C., Basdogan C., Srinivasan M.A. (1999). An Efficient Haptic Rendering Technique for Displaying 3D Polyhedral Objects and Their Surface Details in Virtual Environments, October'99 Vol. 8, No. 5, pp. 477-491, Presence: Teleoperators and Virtual Environments, MIT Press.

11. http://www.sensable.com/products-openhaptics-toolkit.htm 